\title{
Evaluation of Micro-Grid Dynamic Stability in Smart Distribution Grids and Improving it by Adding Additional Control Signal
}

\author{
Manaf HassanNEZHAD ${ }^{1, *}$, Sajad DAVTALAB ${ }^{2}$, Mohammadreza AHMADI ${ }^{3}$
}

1. Young Researchers and Elite Club, Sardasht branch, Islamic Azad University, Sardasht, Iran

2. Islamic Azad University, Urmia branch, Department of Electrical Engineering, Urmia, Iran

3. Islamic Azad University, Urmia branch, Department of Electrical Engineering, Urmia, Iran

\begin{abstract}
In this study, Dynamic Stability studies on smart grids is done locally in the micro grid. A model of the micro-grid includes photovoltaic sources and synchronous generators as well as Interface Converters and induction motors (dynamic load) and finally the governor. First the nonlinear model of micro grid equipment mathematic presented and then how arrangement connection equipment designed. After that state-space model through a linear operating point occurred and also the purpose of the research from the first Lyapanf method to obtain the values of matrix mode achieved its goal. Photovoltaic voltage source converter control is performed by controlling the sliding mode. To ensure the values of the setting MATLAB non Time, calculation conducted through Hifrun Philips taken to the environment and its validity proving was drawn for occurence to enhance the stability of the micro grid through increasing the damping torque oscillation modes, a controller is added to the system that will guarantee in the moments of upheaval.
\end{abstract}

Keywords: smart grid, synchronous generator, photovoltaic, small-signal model, dynamic stability control, power system

\section{Introduction}

By reduction fossil fuels and increasing costs as well as pollution caused by using them, a new revolution happened by replacing smart distribution grids instead of traditional distribution. Following this revolution distributed generation sources will enter into the power grid which for their coordination with the main network, it needs interface converters. in recent years with the rapid progress in the field of power electronics and creation of new opportunities for the application of FACTS devices as an effective way it caused to improve system performance and power transmission limitations [1-3]. If converters not controlled properly they will cause system instability. There are a lot of methods to control them that in this regard, a number of authors studied in researchers (1-6). Among the methods proposed sliding mode controller method has been used, which is a nonlinear MPPT control methods and for linear and nonlinear systems

\footnotetext{
${ }^{1}$ Email: m.h.nezhad9820@gmail.com
} 
controls used for this controller. Since inherently its switching acts discretely, so it applied broadly for power electronic applications. And its switching does not depend to the point of work, orbital parameters and dynamics converter; however it yields high strength [6].

In general, loads divided into two categories: static and dynamic loads dumped into that they are used to arrange for steady state and transient analysis. In modeling, static loads they are usually considered as ZIP load model (composition, constant power, constant current, constant impedance) and dynamic loads as induction motors model. Two basic methods in modeling times are existing Component-based method of load and other time-based approach based on measurement. The method based on components-load is achieved for data load, data load combinations and specifications ingredients load. In a methodology based measurement is used from the data recorded in power plant $[7,8]$ or in a short connecting bus bar distribution network and other data bus for direction load model [9-11]. At the moment of launch, three-phase induction motor acts like a short circuit transformer. As a result, if three-phase induction motor is launched with complete voltage, it takes current about 5 to 8 times the rated current of the network. This remarkable current can cause significant voltage drop in the line feeding that may have undesirable effects on the performance of other user that it is connected to power line [12].

Synchronous generators are main sources of electrical energy in power systems. Large loads move by synchronous motors. Sometimes synchronous condensers used as supply reactive power and voltage control. The basic part of this equipment is similar to each other and in general we call them synchronous machine. Power system stability is a major issue and it must maintain synchronized mode between incorporated synchronous machines. Therefore, understanding the characteristics and accurate modeling of their dynamic reaction has great importance on studying stability of power systems [13].

Within Intelligent grids there are a lot of distributed generation resources that these recourses have large impact on the performance of power systems. Power production of each these sources is dependent on weather conditions and because these condition are changing uncertainly, Therefore the output power of renewable source will be unknown .This creates a mutual impact in the performance and stability of the national grid. Photovoltaic dynamic behavior is about discussed challenge and its impact on the formation of a micro-grid research and its submission.

\section{Micro- Grid Structure}

Micro-grid is examined as in Figure 1-4.Power supplies of this micro-grid is photovoltaic and synchronous generators their load is induction motor. Photovoltaic source is connected to the micro grid by voltage Source converter. And also it applies only active power to the grid. Also it is limited by converter voltage control. Controlling voltage is done through the generator that equipped to automatic voltage regulation (AVR). Finally to complete the governor micro- grid has been added to the synchronous generator. 


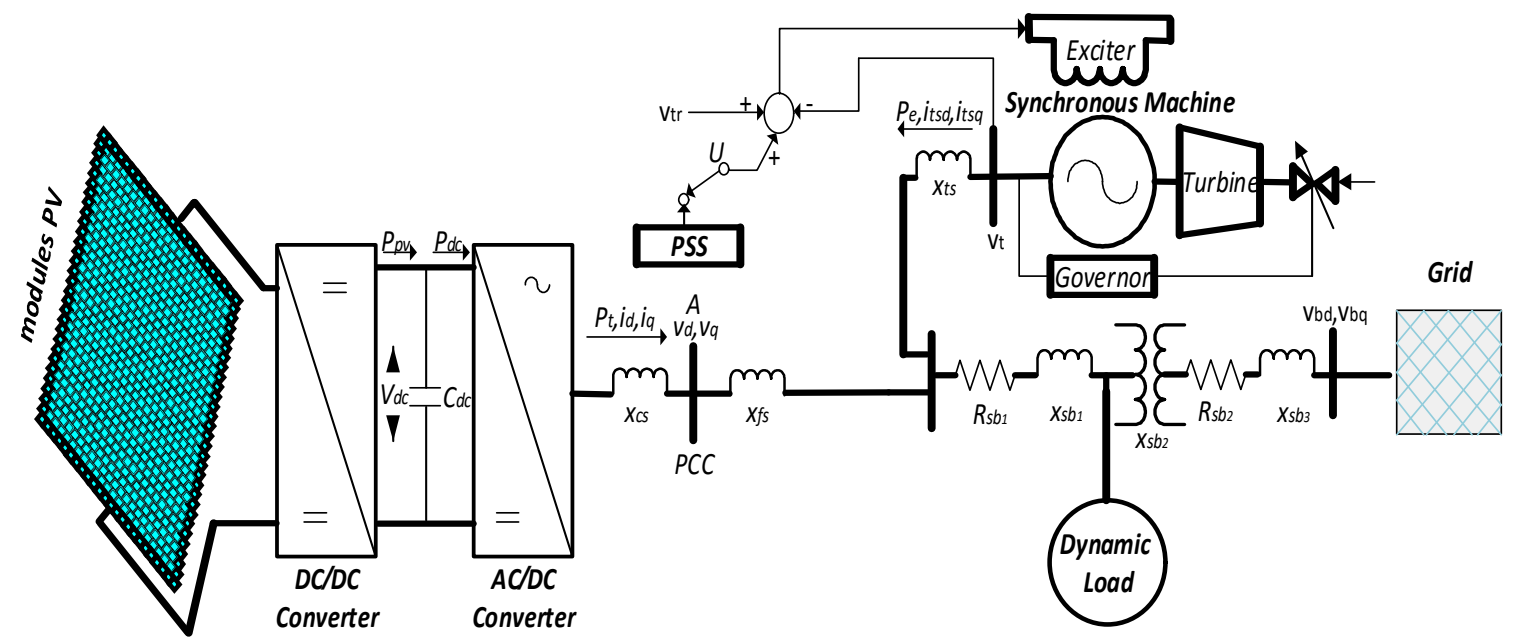

Fig.1: The micro grid of single machine includes synchronous generator - photovoltaicgovernor- induction motor

\section{Equipment Mathematical modeling}

Equipment in the micro- grid is shown by several differential equations as below:

\section{3-1.Induction Motor}

Induction motor model indicate by an oscillation equation (1) two voltage differential equation (2 \& 3) [13].

$$
\begin{aligned}
& \frac{d \omega_{r}}{d t}=\frac{1}{2 H}\left[T_{e}-T_{m}\right] ; \\
& \frac{d v_{d}^{\prime}}{d t}=-\frac{1}{T_{o}^{\prime}}\left[v_{d}^{\prime}+\left(x_{s}-x_{s}^{\prime}\right) i_{q s}\right]+\frac{d \theta_{r}}{d t} v_{q}^{\prime} ; \\
& \frac{d v_{q}^{\prime}}{d t}=-\frac{1}{T_{o}^{\prime}}\left[v_{q}^{\prime}+\left(x_{s}-x_{s}^{\prime}\right) i_{d s}\right]+\frac{d \theta_{r}}{d t} v_{d}^{\prime} ;
\end{aligned}
$$

\section{2-3. Photovoltaic Model}

Generator Model presented as a voltage differential equation (4) and two current differential equation (5\& 6) [14]. 
Bulletin de la Société Royale des Sciences de Liège, Vol. 85, 2016, p. 287 - 303

$$
\begin{aligned}
\frac{d v_{d c}}{d t} & =\frac{\omega}{c_{d c}}\left(\frac{v_{a c b}}{v_{d c b}}\right)^{2}\left(\frac{p_{p v}}{v_{d c}}-\frac{v_{d} i_{d}}{v_{d c}}-\frac{v_{q} i_{q}}{v_{d c}}\right) ; \\
\frac{d i_{d}}{d t} & =\omega i_{q}-\frac{\omega v_{d}}{L_{f}}+\frac{m_{d} \omega v_{d c} v_{d c b}}{L_{f} v_{a c b}} ; \\
\frac{d i_{q}}{d t} & =-\omega i_{d}-\frac{\omega v_{q}}{L_{f}}+\frac{m_{q} \omega v_{d c} v_{d c b}}{L_{f} v_{a c b}} ;
\end{aligned}
$$

\section{3-3. Synchronous Generator}

Synchronous generator and its governor by simplified single-line famous model has been model that they are displayed in the $(7-13)$ equations (15)

$$
\begin{aligned}
& \frac{d \delta}{d t}=\omega_{0}(\omega-1) ; \\
& \frac{d \omega}{d t}=\frac{1}{2 h}\left(p_{m}-p_{e}-D(\omega-1)\right) ; \\
& \frac{d E^{\prime} q}{d t}=\frac{1}{T_{d o}^{\prime}}\left(E_{f d}-E_{q}^{\prime}-\left(x_{d}-x_{d}^{\prime}\right) i_{d}\right) ; \\
& \frac{d E_{f d}}{d t}=\frac{1}{T_{a}}\left(-E_{f d}+k_{a v r}\left(v_{t r e f}-v_{t}\right)\right) ; \\
& \frac{d u_{1}}{d t}=\left(\frac{-1}{T_{2}}\right) u_{1}+\left(\frac{K_{1} K_{2}}{T_{2}}\right) p_{m} ; \\
& \frac{d u_{2}}{d t}=u_{3} ; \\
& \frac{d u_{3}}{d t}=\left(\frac{K_{3}}{k_{2}}+\frac{K_{3} k_{1}}{T_{2} k_{2}}+\frac{K_{3}}{T_{2}^{2}}\right) u_{1}-\frac{1}{k_{2}} u_{2}-\frac{k_{1}}{k_{2}} u_{3}-\left(\frac{k_{1} K_{1} K_{2} K_{3}}{T_{2} k_{2}}+\frac{K_{1} K_{2} K_{3}}{T_{2}^{2}}\right) p_{m} ;
\end{aligned}
$$




\section{4-3. Plasticizers Sliding Mode Controller Designed to Control the Voltage Source Converter}

Two variables $i_{q} \& v_{d c}$ were selected for controller design that the degree of relative to $i_{q}$ is one and for $v_{d c}$ is two. Second order of dc-link voltage with a second-order is shown by (14) equation.

$\frac{d g}{d t}=\frac{A_{1} v_{d}}{v_{d c}}\left(\frac{\omega v_{d}}{x_{c s}}-\omega i_{q}-m_{d} v_{d c} A_{2}\right)+\frac{A_{1} v_{q}}{v_{d c}}\left(\frac{\omega v_{q}}{x_{c s}}+\omega i_{d}-m_{q} v_{d c} A_{2}\right)$

For designed modulation index at first parameters determined as follows:

$e r_{1}=v_{d c}-v_{d c r e f} ; e r_{2}=i_{q}-i_{q r e f}$

$\sigma_{1}=\frac{d\left(e r_{1}\right)}{d t}+k_{1}\left(e r_{1}\right) ; \quad \sigma_{2}=e r_{2}$

$\dot{\sigma}_{1}=\frac{d^{2}\left(e r_{1}\right)}{d t^{2}}+k_{1} \frac{d\left(e r_{1}\right)}{d t} ; \quad \dot{\sigma}_{2}=\frac{d\left(e r_{2}\right)}{d t}$

$\dot{\sigma}_{2}=\frac{d\left(e r_{2}\right)}{d t} ; \quad \dot{\sigma}_{1}=\frac{d^{2}\left(e r_{1}\right)}{d t^{2}}+k_{1} \frac{d\left(e r_{1}\right)}{d t} ;$

$\dot{\sigma}_{1}=-\rho_{1} \operatorname{sign}\left(\sigma_{1}\right) ; \quad \dot{\sigma}_{2}=-\rho_{2} \operatorname{sign}\left(\sigma_{2}\right) ;$

Since the sign function hardly controls and the controller can hardly perform switching operations, it is used rather than a sign of tanh that the switching is done constantly and easier ,so modified (16)equation is done as (17) equation 
Bulletin de la Société Royale des Sciences de Liège, Vol. 85, 2016, p. 287 - 303

$\dot{\sigma}_{1}=-\rho_{1} \tanh \left(\sigma_{1}\right) ; \quad \dot{\sigma}_{2}=-\rho_{2} \tanh \left(\sigma_{2}\right)$

With the (17) dynamic alternative in:

$$
\lambda_{R}=\left[\begin{array}{ll}
\lambda_{1} & \lambda_{2}
\end{array}\right]^{T}=\left(\begin{array}{ll}
\frac{d^{2} v_{d c}}{d t^{2}} & \frac{d i_{q}}{d t}
\end{array}\right)
$$

Equation (19) is obtained as follows:

$$
\lambda_{R}=\left[\begin{array}{l}
\lambda_{1} \\
\lambda_{2}
\end{array}\right]=\left[\begin{array}{c}
-\left(\rho_{1} \tanh \left(\sigma_{1}\right)+k_{1} \frac{d\left(e r_{1}\right)}{d t}\right) \\
-\rho_{2} \tanh \left(\sigma_{2}\right)
\end{array}\right]
$$

After placement $\lambda_{1} \& \lambda_{2}$ in index obtained modulation of nonlinear feedback converter controlled will be transformed. Modulation parameters for equations ( $20 \& 21)$ are.

$$
\begin{gathered}
m_{d}=\frac{A_{3} m_{3}+A_{4} g+A_{7} v_{q}^{2}}{v_{d}}+\frac{A_{6} v_{d}-A_{5} i_{q}}{v_{d c}}+\frac{\left(A_{5}-A_{10}\right) v_{q} i_{d}-A_{11} v_{q}^{2}-A_{8} g^{2}-A_{9} v_{q} m_{4}}{v_{d} v_{d c}} \\
m_{q}=\frac{A_{10} v_{q} i_{d}+A_{11} v_{q}{ }^{2}-A_{9} v_{q} m_{4}}{v_{d} v_{d c}}
\end{gathered}
$$

\section{3- Linearization}

Linear mathematical models of studied equipment is done around the point of the study, which ultimately parameters obtained to state-space model $\dot{X}=A X+B U$, for (22) matrices. 
Bulletin de la Société Royale des Sciences de Liège, Vol. 85, 2016, p. 287 - 303

$$
\begin{aligned}
& A=\left[\begin{array}{cccccccccccccc}
A_{89} & 0 & 0 & 0 & 0 & 0 & 0 & 0 & 0 & 0 & 0 & 0 & 0 & 0 \\
0 & 0 & 1 & 0 & 0 & 0 & 0 & 0 & 0 & 0 & 0 & 0 & 0 & 0 \\
A_{90} & A_{91} & A_{92} & 0 & 0 & 0 & 0 & 0 & 0 & 0 & 0 & 0 & 0 & 0 \\
0 & 0 & 0 & A_{80} & A_{81} & A_{82} & A_{83} & A_{84} & A_{85} & A_{86} & 0 & 0 & A_{87} & A_{88} \\
0 & 0 & 0 & 1 & 0 & 0 & 0 & 0 & 0 & 0 & 0 & 0 & 0 & 0 \\
0 & 0 & 0 & A_{54} & A_{55} & A_{56} & A_{57} & A_{58} & A_{59} & A_{60} & 0 & 0 & A_{61} & A_{62} \\
0 & 0 & 0 & 0 & A_{64} & A_{65} & A_{66} & A_{67} & A_{66} & A_{69} & 0 & 0 & A_{70} & A_{71} \\
0 & 0 & 0 & 0 & 0 & 0 & 0 & 0 & 0 & 0 & 0 & 0 & 0 & 0 \\
0 & A_{72} & 0 & 0 & 0 & A_{73} & A_{74} & A_{75} & A_{76} & A_{77} & 0 & 0 & A_{78} & A_{79} \\
0 & 0 & 0 & 0 & 0 & A_{20} & A_{21} & A_{22} & 0 & A_{23} & A_{63} & 0 & A_{24} & A_{25} \\
0 & 0 & 0 & 0 & 0 & A_{27} & A_{28} & A_{29} & 0 & A_{30} & A_{31} & 0 & A_{32} & A_{33} \\
0 & 0 & 0 & 0 & 0 & A_{34} & A_{35} & A_{36} & 0 & A_{37} & 0 & 0 & A_{38} & A_{39} \\
0 & 0 & 0 & 0 & 0 & A_{40} & A_{41} & A_{42} & 0 & A_{43} & 0 & A_{44} & A_{45} & A_{46} \\
0 & 0 & 0 & 0 & 0 & A_{47} & A_{48} & A_{49} & 0 & A_{50} & 0 & A_{51} & A_{52} & A_{53}
\end{array}\right] \\
& X=\left[\begin{array}{lllllllllllllll}
\Delta u_{1} & \Delta u_{2} & \Delta u_{3} & \Delta g & \Delta_{d} & \Delta_{d} & \Delta_{q} & \Delta \delta & \Delta \omega_{d e} & \Delta E_{q} & \Delta E_{f d} & \Delta \omega_{\text {nind }} & \Delta_{d} & \Delta_{q}
\end{array}\right]^{T} \\
& B=\left[\begin{array}{cccccccccccccc}
0 & 0 & 0 & k_{u 1} & 0 & k_{u 3} & 0 & 0 & 0 & 0 & 0 & 0 & 0 & 0 \\
0 & 0 & 0 & k_{u 2} & 0 & k_{u 4} & k_{u 4} & 0 & 0 & 0 & 0 & 0 & 0 & 0 \\
A_{93} & 0 & A_{54} & 0 & 0 & 0 & 0 & 0 & A_{72} & 0 & 0 & -A_{72} & 0 & 0 \\
0 & 0 & 0 & 0 & 0 & 0 & 0 & 0 & 0 & 0 & k_{u 5} & 0 & 0 & 0
\end{array}\right]^{T} \\
& U=\left[\begin{array}{llll}
v_{\text {dcref }} & i_{\text {qref }} & p_{m} & v_{\text {tref }}
\end{array}\right]^{T}
\end{aligned}
$$

\section{Hefron Philips Model}

After making Linear System, we can use a famous model as Hefron Philips the model shown in Figure 2. This model includes 14 state variables related to the micro-grid equipment and a state variable related to additional control signal. This model is used to show synchronous generator speed changes in the period of time with the arrival of turbulence 


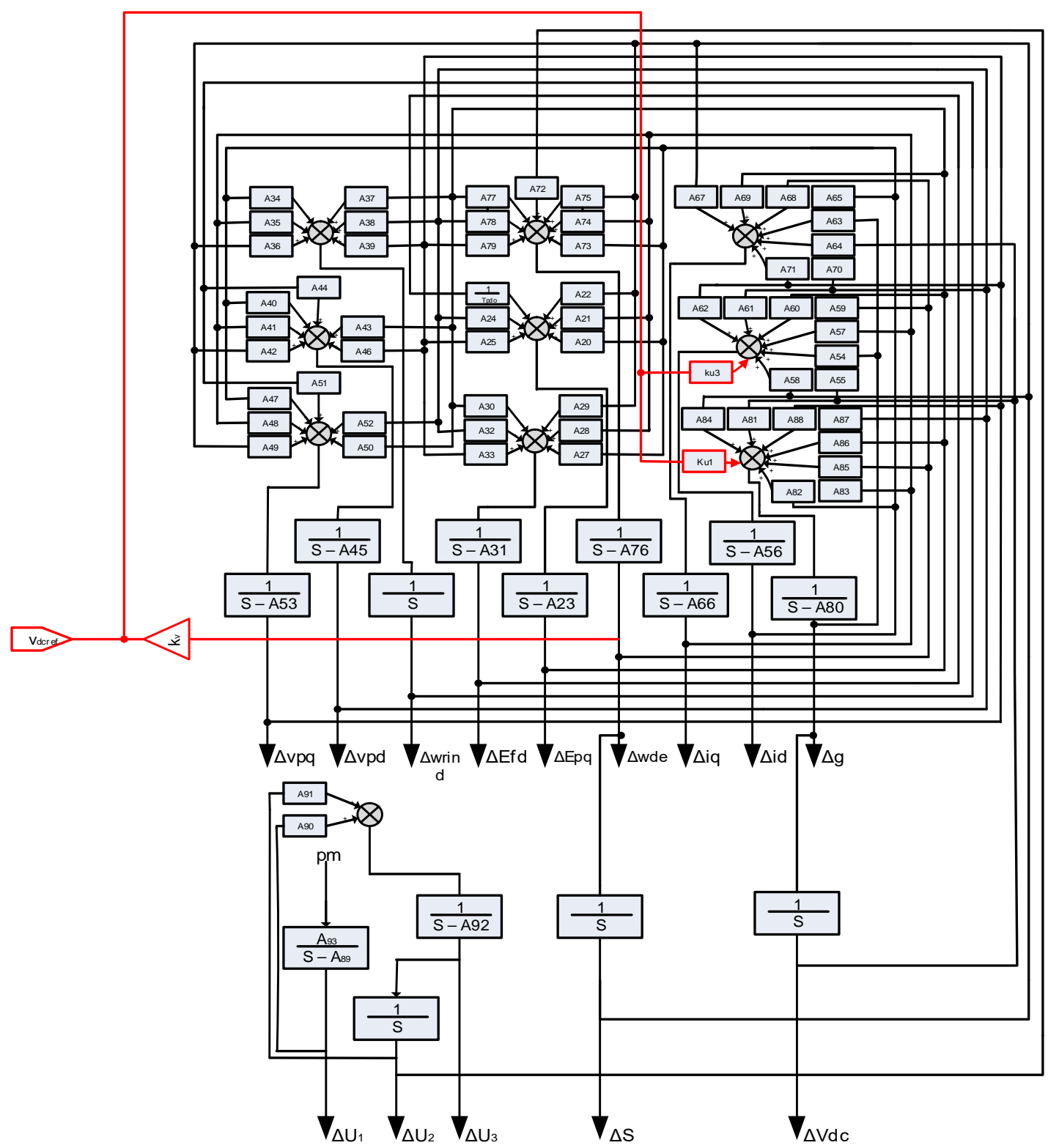

Fig. 2: Micro-grid Hefron Philips Model

\section{Stability Assessment}

If a system analyzed and studied properly, it should be Hefron Philips model and its special values, which are analyzed in two different environments, they had the same results. Therefore they guarantee their accuracy. It should be noted that in order to evaluate the stability of the micro-grid, it is used samples of these two methods. Oscillatory modes Changes of this system are displayed by photovoltaic's power change and by synchronous generator in Table 1 
Bulletin de la Société Royale des Sciences de Liège, Vol. 85, 2016, p. 287 - 303

Table 1: Modes of micro-grid oscillatory

\begin{tabular}{|c|c|c|c|c|}
\hline$p_{d e}$ & $p_{p v}$ & $\lambda_{1}$ & $\lambda_{2}$ & $\lambda_{3}$ \\
\hline $0 / 9$ & $0 / 1$ & $-0 / 06653 \pm 0 / 6695 i$ & $-4 / 6592 \pm 4 / 3361 i$ & $-0 / 5 \pm 0 / 866 i$ \\
\hline $0 / 8$ & $0 / 2$ & $-0 / 01996 \pm 0 / 6969 i$ & $-4 / 5951 \pm 5 / 3080 i$ & $-0 / 5 \pm 0 / 866 i$ \\
\hline $0 / 7$ & $0 / 3$ & $0 / 01295 \pm 0 / 7134 i$ & $-4 / 4800 \pm 6 / 2997 i$ & $-0 / 5 \pm 0 / 866 i$ \\
\hline $0 / 6$ & $0 / 4$ & $0 / 03224 \pm 0 / 7209 i$ & $-4 / 3226 \pm 7 / 3874 i$ & $-0 / 5 \pm 0 / 866 i$ \\
\hline $0 / 5$ & $0 / 5$ & $0 / 04254 \pm 0 / 7163 i$ & $-4 / 1372 \pm 8 / 6601 i$ & $-0 / 5 \pm 0 / 866 i$ \\
\hline $0 / 4$ & $0 / 6$ & $0 / 05860 \pm 0 / 6920 i$ & $-3 / 9636 \pm 10 / 250 i$ & $-0 / 5 \pm 0 / 866 i$ \\
\hline $0 / 3$ & $0 / 7$ & $0 / 11173 \pm 0 / 6440 i$ & $-3 / 9134 \pm 12 / 376 i$ & $-0 / 5 \pm 0 / 866 i$ \\
\hline $0 / 2$ & $0 / 8$ & $0 / 23488 \pm 0 / 5792 i$ & $-4 / 1936 \pm 15 / 485 i$ & $-0 / 5 \pm 0 / 866 i$ \\
\hline $0 / 1$ & $0 / 9$ & $0 / 50911 \pm 2 / 2035 i$ & $-4 / 7069 \pm 24 / 119 i$ & $-0 / 5 \pm 0 / 866 i$ \\
\hline
\end{tabular}

In small signal studies, stability reviews conducted in this way that non-oscillatory special values must be negative and for the Eigen values of the oscillatory in addition to negative condition of real part, it should also have distance from the imaginary axis (The purpose of stability is dynamic stability in asymptotic component). If we look carefully in Table 1, we can see that there are three oscillatory modes in micro-grid, that the real part of the first oscillatory modes in pde $=$ $0 / 7$, is positive .As a result from this arrangement, the system will become unstable. The results of Hefron Philips model is presented in Figure 3.

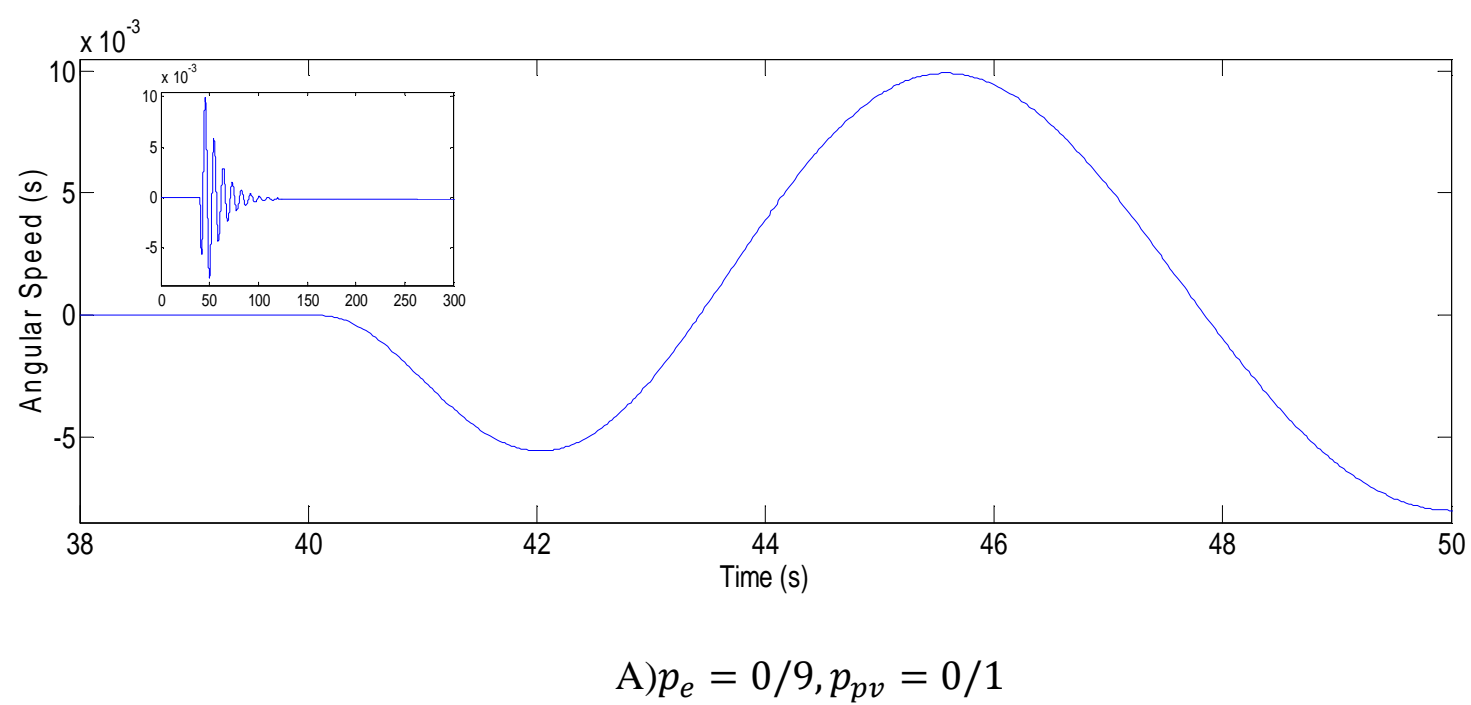


Bulletin de la Société Royale des Sciences de Liège, Vol. 85, 2016, p. 287 - 303

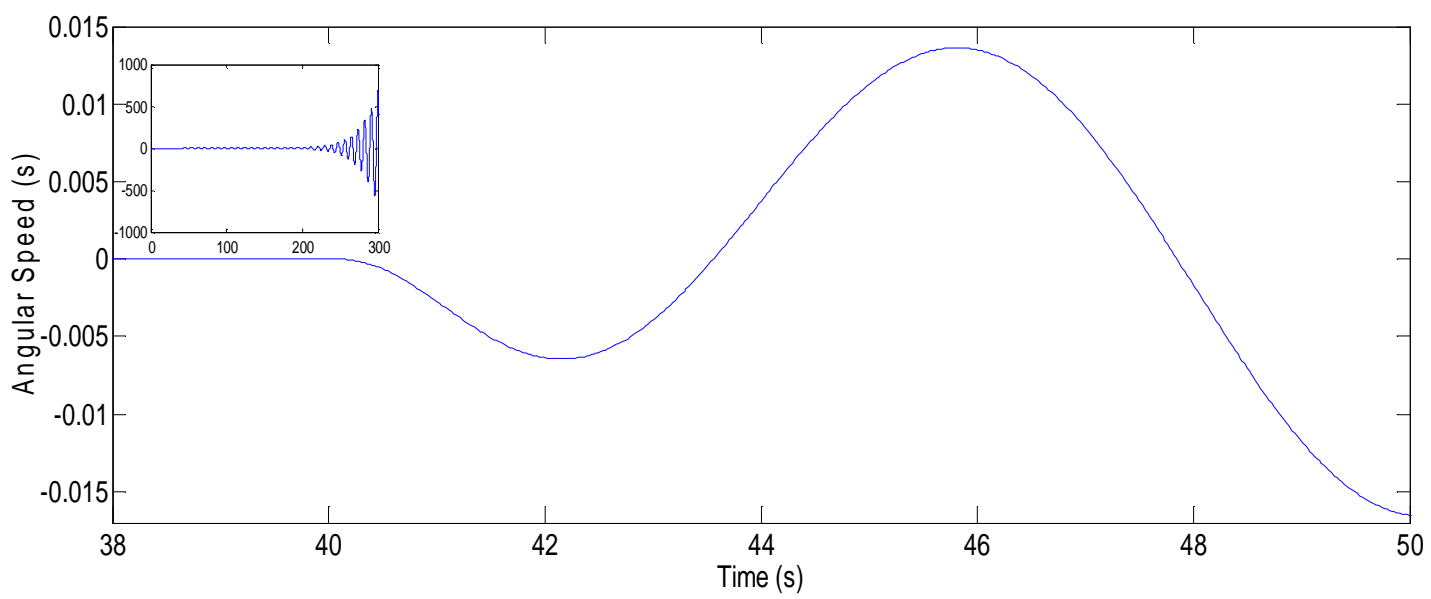

(B) $p_{e}=0 / 5, p_{p v}=0 / 5$

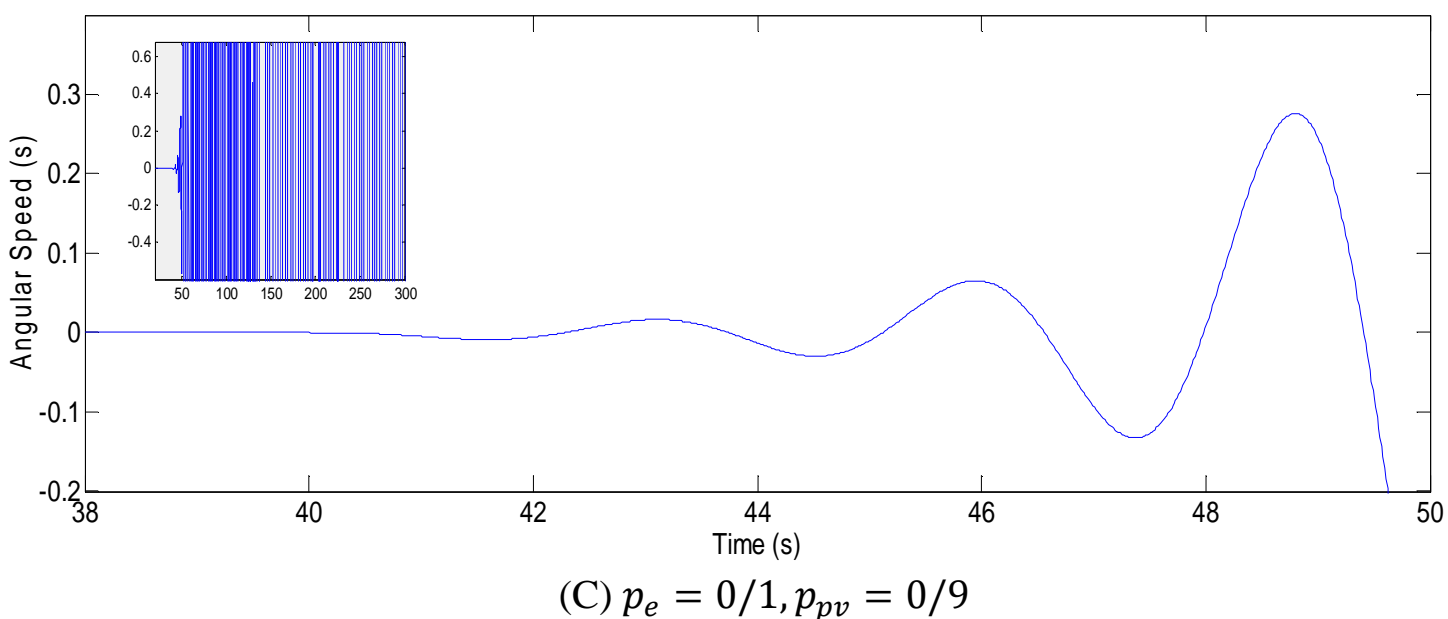

Fig.3: The angular speed synchronous generator in different arrangements sources

To search the exact impact of each Eigen values in the stability, the damping ratio defines its existence with a reduced rate of oscillation amplitude. Its concept is in action and during the upheaval; the ability of any of the modes in actions has destructive or adverse impact on the stability of the system. If the amount of it is small, the ability of related mode is more in disorder of the stability, for specific amounts $\lambda=\sigma \pm j \omega$ damping ratio calculated from (21) formula.

$$
\zeta=\frac{-\sigma}{\sqrt{\sigma^{2}+\omega^{2}}}
$$


With the change of resources power in the micro-grid, Hermedan damping ratio changes. For a number of different arrangements of these resources, damping ratio of oscillatory modes is shown in Table 2. In this table, we can see that by reducing the generator, damping torque reduces.

Table .2: Damping Ratio of Oscillation Modes

\begin{tabular}{|c|c|c|c|c|}
\hline$p_{d e}$ & $p_{p v}$ & $\lambda_{1}$ & $\lambda_{2}$ & $\lambda_{3}$ \\
\hline $0 / 9$ & $0 / 1$ & $0 / .98888$ & $0 / 73204$ & $0 / 5$ \\
\hline $0 / 6$ & $0 / 4$ & $-0 / 04467$ & $0 / 50503$ & $0 / 5$ \\
\hline $0 / 4$ & $0 / 6$ & $-0 / 084307$ & $0 / 36067$ & $0 / 5$ \\
\hline $0 / 1$ & $0 / 9$ & $-0 / 225120$ & $0 / 19154$ & $0 / 5$ \\
\hline
\end{tabular}

The first and second oscillatory modes cause concern, because their presence in the system, eventually causing it to be unstable. But the third oscillatory modes enough damped and there is no concern about its presence. According to the results by changing the output power generators and photovoltaic, major changes creates in work point and generator angular torque and performance change of electrical equipment whereby its adverse impact may lead to the generator output from studied line and creating fruitful loads by connecting loads to a micro-grid or another line, sequential output and ultimately the extinction of subscribers.

So there is a need for a controller that by changes in the output power of recourses and load variations by applying an additional control signal, it damps disturbances caused by these changes. Due to the lack of adequate information related to the time and the scope of disturbances used from the feedback control method. To solve the mentioned problem about first and second modes, it is recommended that additional control signal apply to the system.

\section{The proposed Additional Control Signal}

In this arrangement which feedback is taken from speed synchronous generator and it applies to $v_{\text {dcref }}$, its equation states in (22):

$v_{\text {dcref }}=v_{\text {dcref } 0}+k_{v} \Delta \omega$

In this control signal $v_{\text {dcref }}$ 'it was as an input in the previous case in the system, but in this episode, it considers as the state variable. In addition to the angular speed of synchronous 
Bulletin de la Société Royale des Sciences de Liège, Vol. 85, 2016, p. 287 - 303

generator is highly dependent on the frequency change and it reflects the smallest deviation in the frequency, so we can use it to obtain $v_{d c r e f}$.

Special values are highly dependent on the $k_{v}$ quantity and with minor deviation in it they change heavily, so we should carefully specify them. To see the changes on the system modes, we considered $k_{v}=-8$ and they collected in Table 3 .

For interest above $\lambda_{1}$ oscillatory modes pulled to the left of imaginary axis, but one of the special values goes in the array of $p_{e}=0 / 1, p_{p v}=0 / 9$ resources in the right of the axis. So it should be selected more than this amount that according to investigations conducted the most optimized is -4.5 that by ((trial and error)) it is obtained. The trajectory of two specific values $\lambda_{1}, \lambda_{2}$ is presented in Figure 5, in this figure we can see that by increasing the optimum that mentioned, swinging mode on the left $\lambda_{1}$ and mode on the right $\lambda_{2}$ move in the imaginary axis.

Table 3: Modes of oscillatory by adding the first control signal

\begin{tabular}{|c|c|c|c|c|}
\hline$p_{d e}$ & $p_{p v}$ & $\lambda_{1}$ & $\lambda_{2}$ & $\lambda_{3}$ \\
\hline $\begin{array}{l}0 \\
/ 9\end{array}$ & $0 / 1$ & 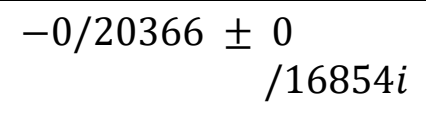 & $\begin{array}{r}-0 / 01244 \pm 5 \\
/ 7903 i\end{array}$ & $-0 / 5 \pm 0 / 866 i$ \\
\hline $\begin{array}{l}0 \\
/ 8\end{array}$ & $0 / 2$ & 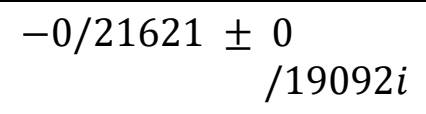 & $-0 / 07786 \pm 6$ & $-0 / 5 \pm 0 / 866 i$ \\
\hline $\begin{array}{l}0 \\
/ 7\end{array}$ & $0 / 3$ & $-0 / 23146 \pm 0 / 21683 i$ & $\begin{aligned}-0 / 15629 \pm{ }_{/ 7543 i}\end{aligned}$ & $-0 / 5 \pm 0 / 866 i$ \\
\hline $\begin{array}{l}0 \\
/ 6\end{array}$ & $0 / 4$ & $-0 / 25109 \pm 0 / 24825 i$ & $-0 / 25406 \pm \frac{7}{/ 4808 i}$ & $-0 / 5 \pm 0 / 866 i$ \\
\hline $\begin{array}{l}0 \\
/ 5\end{array}$ & $0 / 5$ & $\begin{aligned} &-0 / 27829 \pm 0 \\
& / 28833 i\end{aligned}$ & $\begin{aligned} &-0 / 38583 \pm 8 \\
& / 4700 i\end{aligned}$ & $-0 / 5 \pm 0 / 866 i$ \\
\hline $\begin{array}{l}0 \\
/ 4\end{array}$ & $0 / 6$ & $-0 / 31988 \pm 0 / 34264 i$ & $\begin{aligned}-0 / 59308 \pm & 9 \\
& / 8562 i\end{aligned}$ & $-0 / 5 \pm 0 / 866 i$ \\
\hline $\begin{array}{l}0 \\
/ 3\end{array}$ & $0 / 7$ & 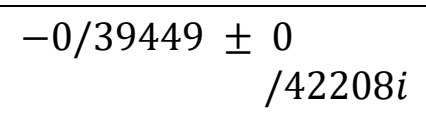 & $-1 / 00320 \pm \operatorname{li}_{/ 874 i}$ & $-0 / 5 \pm 0 / 866 i$ \\
\hline $\begin{array}{l}0 \\
/ 2\end{array}$ & $0 / 8$ & $-0 / 61138 \pm 0$ & $-1 / 94790 \pm \begin{array}{l}15 \\
/ 021 i\end{array}$ & $-0 / 5 \pm 0 / 866 i$ \\
\hline $\begin{array}{l}0 \\
/ 1\end{array}$ & $0 / 9$ & $\begin{aligned}-0 / 15463 \pm & 3 \\
& / 99450 i\end{aligned}$ & $-3 / 84970 \pm \begin{array}{l}23 \\
/ 783 i\end{array}$ & $-0 / 5 \pm 0 / 866 i$ \\
\hline
\end{tabular}


Bulletin de la Société Royale des Sciences de Liège, Vol. 85, 2016, p. 287 - 303

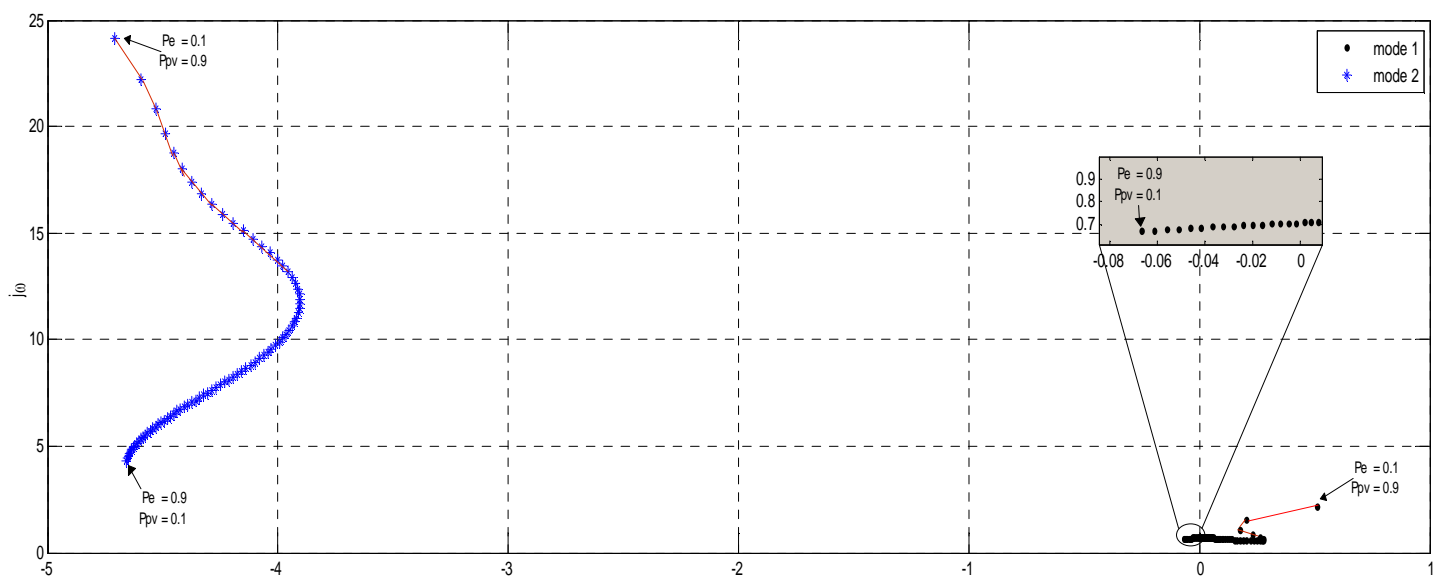

A $) \mathbf{k v}=\mathbf{0}$

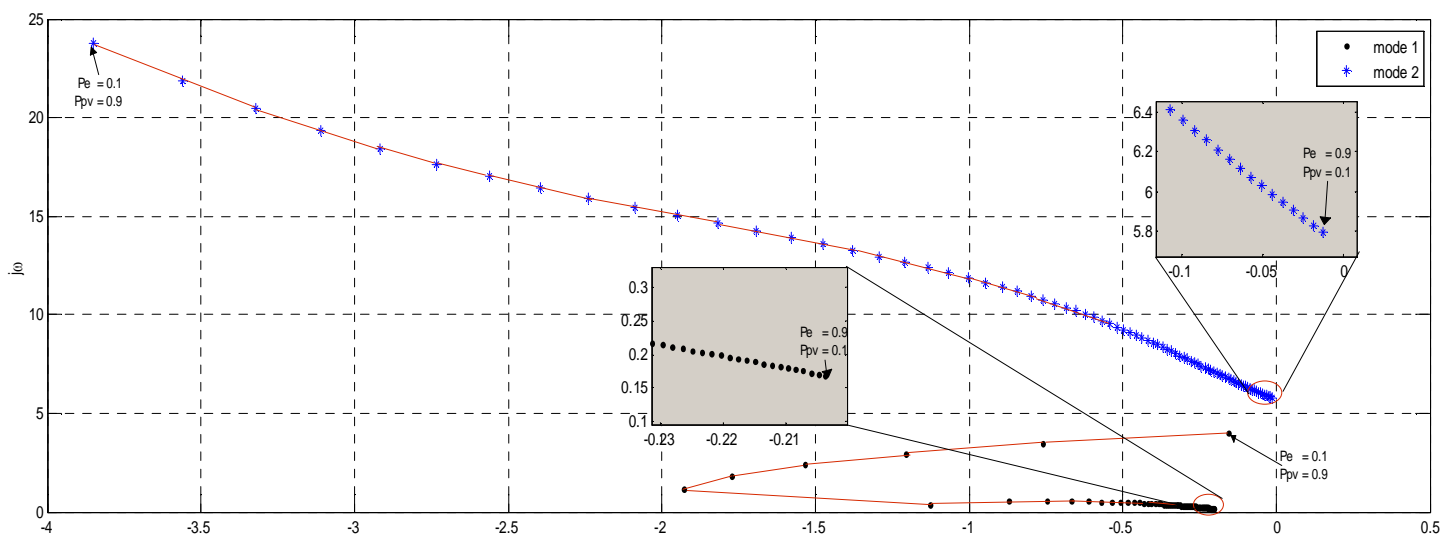

B) $\mathbf{k v}=\mathbf{- 8}$

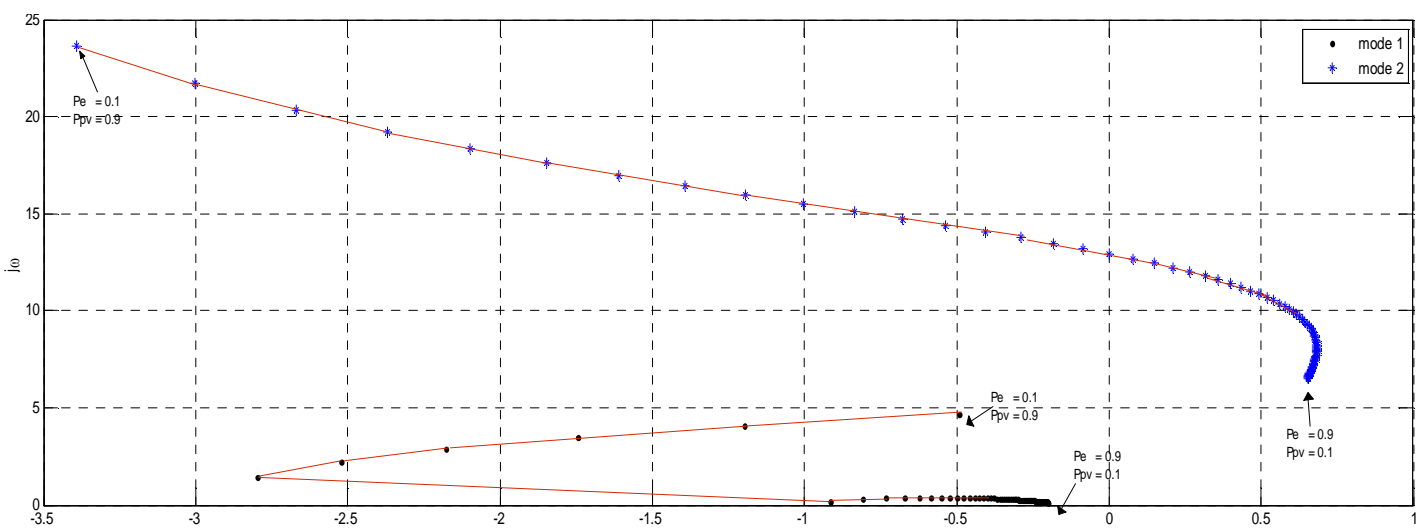

C) $\mathrm{kv}=\mathbf{- 1 2}$ 
Bulletin de la Société Royale des Sciences de Liège, Vol. 85, 2016, p. 287 - 303

Fig.4: The trajectory of $\lambda_{1} \& \lambda_{2}$ modes by Changing Interest

The result of the first time simulation control signal in Figure 5 (A, B, C \& D) was shown.

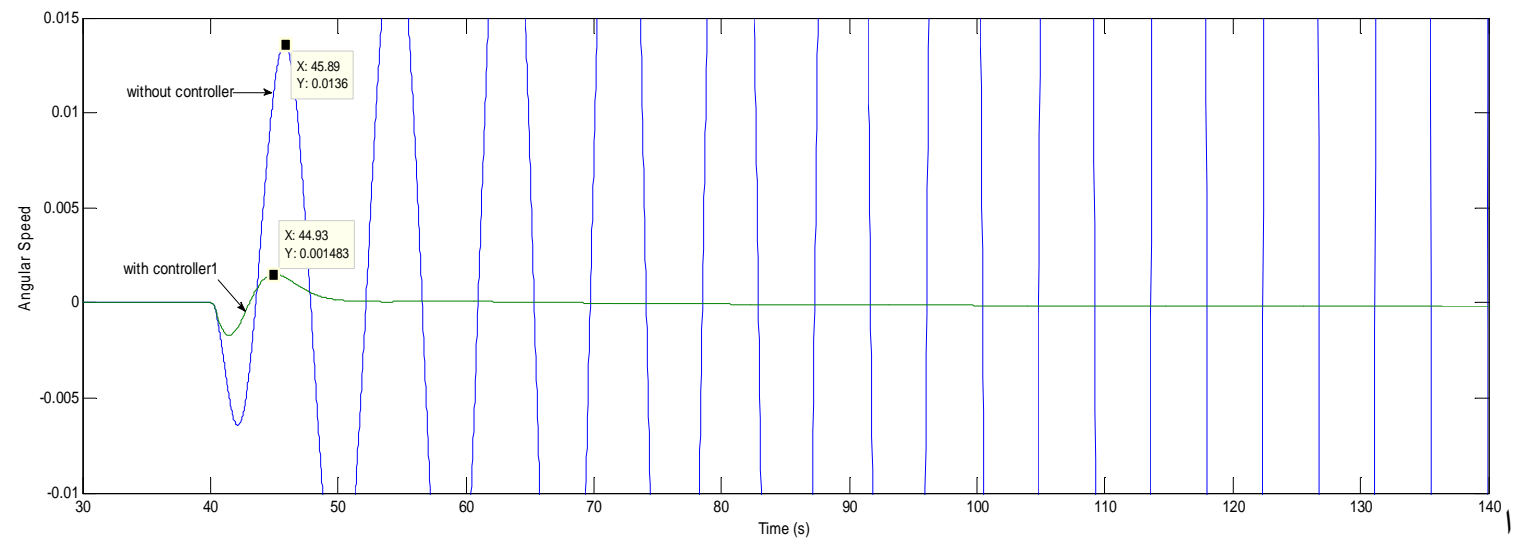

A) $p_{e}=0 / 9, p_{p v}=0 / 1$

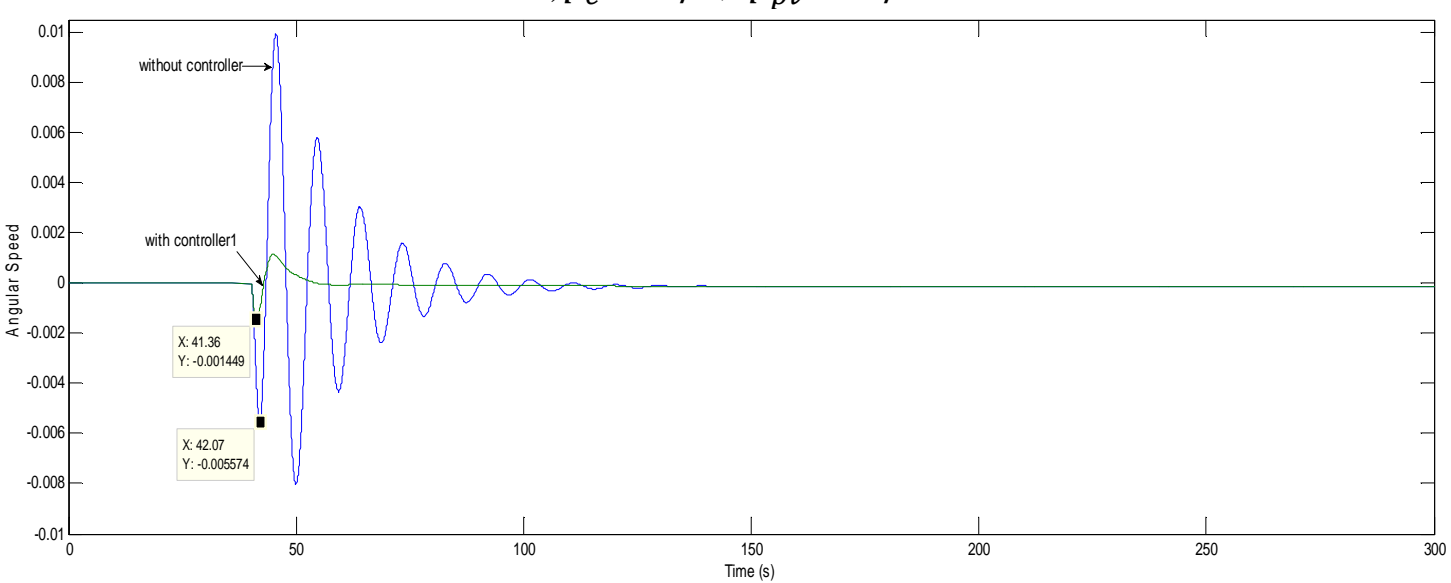

B) $p_{e}=0 / 5, p_{p v}=0 / 5$

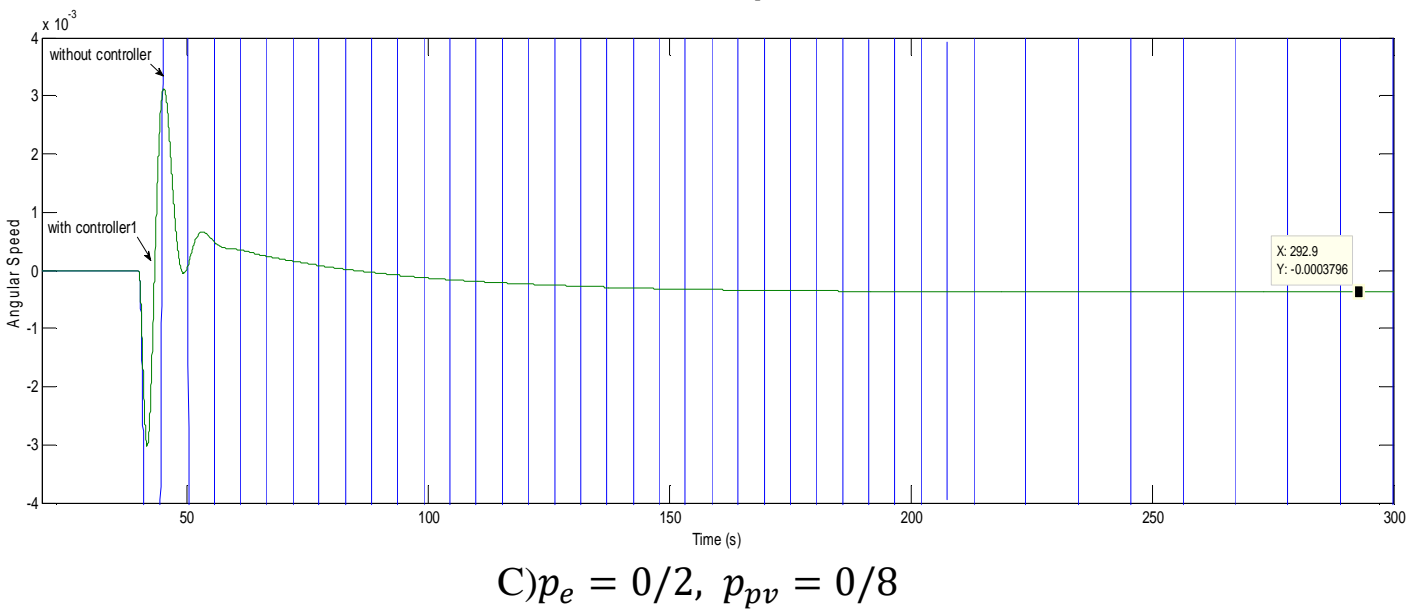




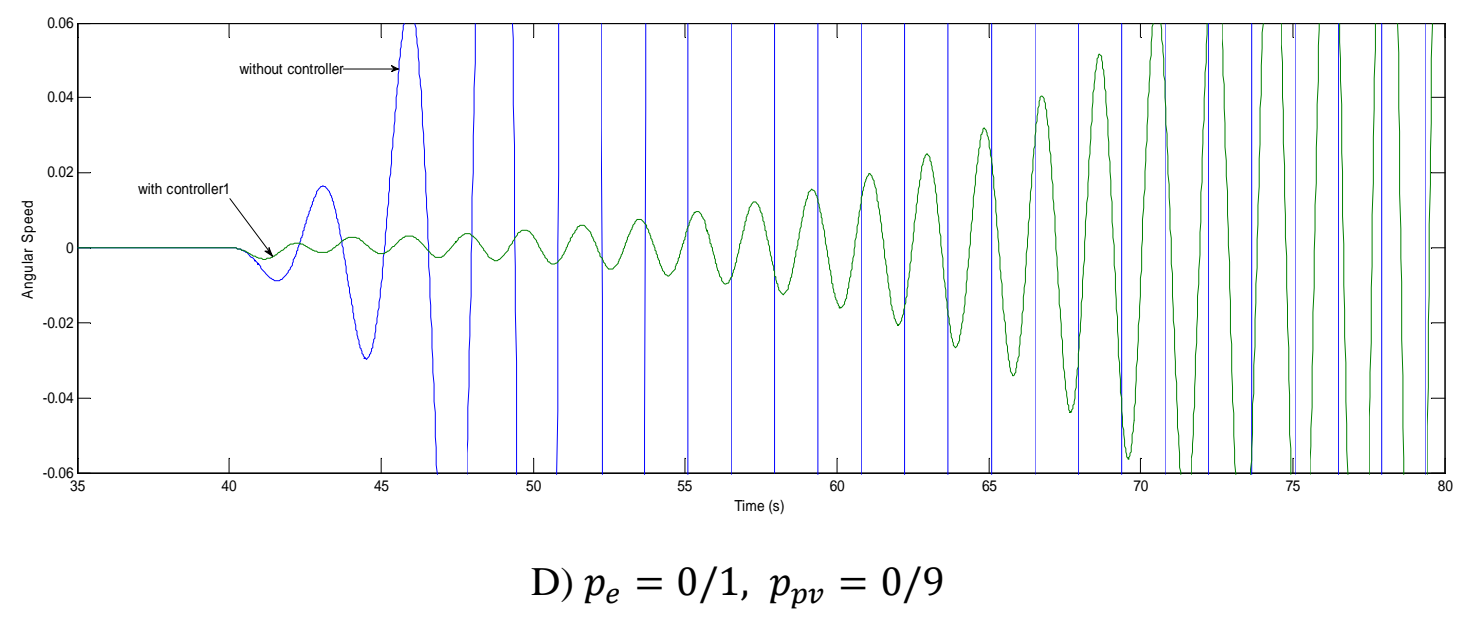

Fig. 5: Angular speed synchronous generator along with the former controller with the interest

$$
k_{v}=-4 / 5
$$

In Figure 5, we conclude that the applied disturbance to the synchronous generator damped well by adding control signal and the system is stable until the array $p_{e}=0 / 2, p_{p v}=0 / 8$ and after this arrangement the real part of first mode will be positive .And one of the Eigen values continues to the right part of the imaginary axis and the system becomes unstable. Another thing discussed not reaching zero error after damping operations that you can see in Figure 6-C.

\section{Conclusions}

In Intelligent grids ,there are a lot of DGs that these resources have a great impact on power system operation.To improve the power system stability, Increasing Reliability, Providing affordable power supply, Energy saving and environmental issues has been more attention to applied DG is in the power system. High energy productivity, low environmental impacts and using them as emergency power, are some advantages of DG.

Power production of Each DG is dependent on weather conditions and because these conditions are changing uncertainly, so the power output of renewable resources are unknown. Therefore, each of mentioned sources such as photovoltaic has a certain dynamic behavior.In studied microgrid power of synchronous generator and its torque angle was dependent on the power output of photovoltaic, so according to the mentioned reasons, dynamic behavior of the micro-grid will be varied. To control this behavior and correct it as continued studies, investigations were carried out and submitted.

At first, it was required that the ways of changing behavior of equipments specified over time, which mathematical modeling defines their dominance behavior. To evaluate the effect of each of the equipment on each other and finally on the micro-grid, Linearization of Operating point, It was its duty that resulted in creation of the state space model. To evaluate the stability of the 
micro-grid by using matrix mode, the first definition of Liyapanof and Eigen values happened. It should be noted that to control the converter it was used from sliding mode control that by taking advantage of it, the modulation indexes were designed and extracted. To see the accuracy of results in mode matrix and the Eigen values in the time environment, it was need the interface Philips Hefron model. In this regard, a presentational layout evaluated. A micro-grid controller was designed to increase stability that in the perturbation state ,controllers that they were in feedback position, at any moment they measured the error signal and compared with the reference value .And according to the deviation caused they add an additional control signal to the system.

Through influential photovoltaic resources, dynamic Stability power grid changes drastically.Also by increasing power output of mentioned source, synchronous generator power required to be reduced whereby synchronous torque was increased and with this increase, the amount of damping torque was reduced.

In the absence of controller in the system changing of dc link reference voltage and synchronous generator power will be possible to change the damping torque

\section{Reference}

[1] G. Zhang and Z. Xu, "Steady-state model for VSC based HVDC system and its controller design," in Proc. IEEE Power Eng. Soc. Winter Meeting, Jan./Feb. 2001, vol. 3, pp. 10851090.

[2] G. B. Zhang, Zexel, and G. Z. Wang, "Steady state model and its nonlinear control of VSCHVDC system,"Proc. CSEE, vol. 22, pt. 1, pp. 17-22, 2002.

[3] M. Durrant, H. Werner, and K. Abbott, "Synthesis of multi-objective controllers for a VSC HVDC terminal using LMIs," inProc. IEEE Conf. Decision and Control, Dec. 2004, pp. 4473-4478.

[4] S. Y. Ruan, G. J. Li, X. H. Jiao, Y. Z. Sun, and T. T. Lie, "Adaptive control design for VSCHVDC system based on backstepping approach," Elect. Power Syst. Res., vol. 77, no. 5-6, pp. 559-565, Apr. 2007.

[5] D. Aravindan, G. S. Ilango, C. Nagamani, and A. V. S. S. R. Sai, "Power oscillation damping using UPFC in automatic power flow control mode with constant power reference," in Proc. Int. Conf. Power and Energy System, Baltimore, MD, Apr. 16-18, 2008, pp. 144-149.

[6] A. Moharana and P. Dash, "Input-output linearization and robust slidingmode controller for the VSC-HVDC transmission link,"IEEE Trans. Power Del., vol. 25, no. 3, pp. 1952-1961, Jul. 2010.

[7] J. H .Shi, H. Renmu, "Measurement- based load Modeling- Model structure", 2003 IEEE Bologna Power Tech Conference.

[8] He Renmu, Ma Jin and David j.Hill, "Composite Load Modeling via Measurment Approach", IEEE Trans actions On Power System, VOL. 21, NO. 2, MAY 2006. 
Bulletin de la Société Royale des Sciences de Liège, Vol. 85, 2016, p. 287 - 303

[9] B. Kim, H. Kim, B. Lee, "Parameter Estimation for the Composite Load Model, "Journal of International Council on Electrical Engineering, Vol. 2, No. 2, pp. 215-218, march 2012.

[10] J. Ma, "Measurement- based load Modeling using Genetic Algorithms", IEEE Congress on Evolutionary Computation (CE2 C 007), 2007.

[11] D. Singh, R. K. Misra, and D. Singh, "Effect of Load Models in Distributed Generation Planning," 2007 IEEE.

[12] IEEE Task Force Report, "Load Representation for Dynamic Performance Analysis," Peper 92WM126-3 PWRD, presented at the IEEE PES Winter Meeting, New York, January 26-30, 1992.

[13] P. Kundur, Power system stability and control. New York: Mc Graw Hill, 1993.1.

[14] S. Mishra, D. Ramasubramanian and P.C. Sekhar, "A seamless control methodology for a grid connected and isolated PV-diesel microgrid,".Power Systems, IEEE Transactions on, 28(4), pp.4393-4404, 2013.

[15] P. Anderson and A. Fouad, Power System Control and Stability, $2^{\text {nd }}$ ed. New Delhi, India: Wiley India, 2008. 